\title{
Anti-candidal activity of Astragalus verus in the in vitro and in vivo guinea pig models of cutaneous and systemic candidiasis
}

\section{Ali Mikaeili, ${ }^{1}$ Isaac Karimi, ${ }^{*}, 2$ Tayebeh Shamspur, ${ }^{3}$ Babak Gholamine ${ }^{4}$ Masoud Modaresi, ${ }^{5}$ Ali Khanlari ${ }^{4}$}

\author{
${ }^{1}$ Department of Medical Mycology, School of Medicine, Kermanshah University of \\ Medical Sciences, Iran, \\ ${ }^{2}$ Department of Biochemistry, Physiology and Pharmacology, College of Veterinary \\ Medicine, Razi University, Kermanshah, Iran, \\ ${ }^{3}$ Phytochemistry Group, Department of Chemistry, Shahid Bahonar University of \\ Kerman, Iran, \\ ${ }^{4}$ Department of Pharmacology, School of Pharmacy, Kermanshah University of Medical \\ Sciences, Iran, \\ ${ }^{5}$ Department of Pharmacognosy and Pharmaceutical Biotechnology, School of \\ Pharmacy, Kermanshah University of Medical Sciences, Iran.
}

Revista Brasileira de Farmacognosia Brazilian Journal of Pharmacognosy

Received 23 Aug 2011

Accepted 14 Jan 2012 Available online 20 Mar 2012
22(5): 1035-1043, Sep./Oct. 2012

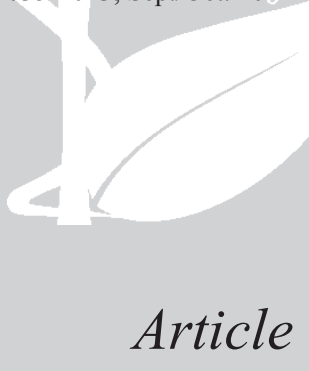

\section{Article}

\begin{abstract}
This study was design to evaluate the anti-candidal activity of Astragalus verus Olivier, Fabaceae (Av). The GC/MS analysis of essential oils of Av showed that aqueous extract contains thymol while hexadecanoic acid, 1,2-benzenedicarboxylic acid, diisooctyl ester and phytol were found as major components of methanol and acetone extracts. The aqueous extract showed anti-candidal activity in the concentration $320 \mathrm{mg} / \mathrm{mL}$ using disc diffusion method and its minimum inhibitory concentration (MIC) was $160 \mathrm{mg} / \mathrm{mL}$. To induce cutaneous candidiasis, the dorsum of immunocompromised guinea pigs was infected with Candida albicans and animals were divided into five groups $(\mathrm{n}=5$ for each): $\mathrm{NC}$, received a vehicle; PC, received topical ketoconazole $2 \%$ and three other groups which received topical 10, 20 and $40 \%$ aqueous extract of Av. On ninth day postinfection, skins were cultured and colony forming unite per gram (CFU/g) skin was recorded. Systemic candidiasis was obtained by intravenous inoculation of $C$. albicans, $4000 \mathrm{CFU} / \mathrm{g}$ body weight. Here, animals have been divided into five groups like cutaneous candidiasis but their medications have been delivered in drinking water for ten days before induction of infection. On second day postinfection, all internal tissues were taken for determining $\mathrm{CFU} / \mathrm{g}$ tissue. The aqueous extract (40\%) prevented heavy burden of C. albicans in tissues and skin in oral and topical application, respectively. The results indicate that Av represents a potential source of anti-candidal drug.
\end{abstract}

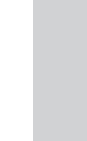


of conditions or medications that promote the overgrowth of yeast cells, either because they kill beneficial normal flora, or because they interfere with normal functions of immune and neuroendocrine systems. These medications include: antibiotics; chemotherapy, hormone replacement, corticosteroids, and oral contraceptives (Clemons \& Stevens, 2000, 2001). Inappropriate diet, such as over-consumption of yeast products, sugar, or alcohol, also can promote yeast growth. Those people with immune system or endocrine gland disorders are more prone to candidiasis, such as patients with acquired immunodeficiency diseases, cancer, or diabetes mellitus (Clemons \& Stevens, 2000, 2001).

Nowadays, the multiple drug resistance in different pathogenic microorganisms to commonly used antibiotics leads to search for new antimicrobial agents to combat infections and overcome problems of resistance and side effects of the currently available antimicrobial agents (Ali-Shtayeh et al., 1998; Primo et al., 2001; Karaman et al., 2003). As far as our literature survey could ascertain, neither the anti-candidal activities of the essential oils of Av nor the composition of the oils of Av have been studied before, although there was a report concerning the antidermatophytic activity of Av aqueous extract that we reported recently (Mikaeili et al., 2011). Hence, this study was aimed to find partial chemical composition of the essential oil and anti-candiadal activity of different extracts of $\mathrm{Av}$ in the in vitro and in guinea pig models of cutaneous and systemic candidiasis.

\section{Material and Methods}

\section{Plant collection and authentication}

The aerial parts of Astragalus verus Olivier, Fabaceae, were collected from Khalichian village Mountains at Sanandaj, Iran in August 2010 and air dried in the shade. It was authenticated by Dr. Nastaran Jalilian, botanist in Research Herbarium of Jahad-Keshavarzi Organization, Kermanshah province of Iran. Aerial parts $(15 \mathrm{~kg})$ of dried Av were ground in an electric grinder to produce a fine powder.

\section{Preparation of extracts}

Aqueous decoction

Aqueous decoctions were prepared by boiling $50 \mathrm{~g}$ Av powder in $500 \mathrm{~mL}$ sterile boiled distilled water with continuous shaking over a heater-stirrer at the $50^{\circ} \mathrm{C}$ for $12 \mathrm{~h}$. The flasks were then plugged and removed from heat and allowed to cool for $45 \mathrm{~min}$. After cooling, the contents of the flasks were filtered with double filter paper and sterile filters to remove any impurities (Runyoro et al., 2006; Chaudhry \& Tariq, 2008). The filtrate was dried in rotary evaporator to obtain the aqueous extract (AE; $2.575 \mathrm{~g} ; 5.150 \% \mathrm{w} / \mathrm{w})$.

\section{Methanol and acetone maceration}

About $50 \mathrm{~g}$ of Av powder was extracted with 1.5 $\mathrm{L}$ of methanol by cold maceration for $24 \mathrm{~h}$ and filtered for three rounds. After cooling, the contents of the flasks were filtered with double filter paper and sterile filters to remove any impurities (Runyoro et al., 2006; Chaudhry \& Tariq, 2008). The filtrate was dried in rotary evaporator to obtain the methanol extract (ME; $1.686 \mathrm{~g} ; 3.372 \% \mathrm{w} / \mathrm{w}$ ). The resulting powder was dissolved in $80 \mathrm{~mL}$ of methanol plus $40 \mathrm{~mL}$ of chloroform, a minimum ratio of two solvents. The similar methodology was applied to obtain acetone extract (AcE $2.569 \mathrm{~g} ; 5.138 \% \mathrm{w} / \mathrm{w}$ ). Here, the resulting powder was dissolved in $80 \mathrm{~mL}$ of acetone plus $25 \mathrm{~mL}$ of chloroform, a minimum ratio of two solvents. The sample extracts were kept in the refrigerator $\left(4{ }^{\circ} \mathrm{C}\right)$ until the analyses were accomplished.

\section{Preparation of essential oils}

The essential oils were obtained from dried powdered of aqueous, methanol and acetone extracts of Av by steam distillation for $3 \mathrm{~h}$, using a Clevenger apparatus.

\section{Essential oil chemical analysis}

Gas chromatography (GC) analysis of resulting essential oils of $\mathrm{AE}, \mathrm{ME}$ and $\mathrm{AcE}$ extracts of $\mathrm{Av}$ was performed using a Hewlett-Packard chromatograph 5890 series equipped with FID detector and a HP-1 fused silica column $(30 \mathrm{~m} \times 0.25 \mathrm{~mm}$ and film thickness $0.25 \mu \mathrm{m})$. GC/MS analysis was carried out on a Hewlett-Packard 5973 connected with a mass detector HP 6890 using a HP-1 column $(30 \mathrm{~m} \times 0.25 \mathrm{~mm}$ and film thickness 0.25 $\mu \mathrm{m})$. Oven temperature programming was $40-250{ }^{\circ} \mathrm{C}$ with an increase of $3{ }^{\circ} \mathrm{C} / \mathrm{min}$ for both GC/FID and GC/ MS. Injector and detector temperatures were 320 and 310 ${ }^{\circ} \mathrm{C}$, respectively. The carrier gas was helium and flew at a rate of $1 \mathrm{~mL} / \mathrm{min}$. The mass spectrometer was operated at $70 \mathrm{eV}$ with the mass range, $40-350 \mathrm{amu}$ and scan time $1 \mathrm{~s}$.

Identification was based on sample retention data and comparison with authentic standards, computer matching using NIST MS library. The identification was also confirmed by comparison of the retention indices with data in the literature (Adams, 1996; Shibamoto, 1987). The percentages of compounds were calculated by the area normalization method without considering response factors. The retention indices were calculated for all volatile constituents using a homologous series of $n$-alkanes. 


\section{Antimicrobial tests}

In vitro antifungal assay: preparation of inocula

The fungal cultures of $C$. albicans isolates (ATCC 10231) were grown on Sabouraud dextrose agar (SDA; Merck, Germany) plates at $28 \pm 2{ }^{\circ} \mathrm{C}$ for two weeks. The conidia fungi were collected using sterile normal saline solution (NS) on the agar surface followed by gentle shaking. The suspension was vortexed and heavy particles were allowed to settle for 3-5 min. The inocula were prepared spectrophotometrically to give a final concentration of $1.0 \times 10^{6} \mathrm{CFU} / \mathrm{mL}$ in NS (NCCLS, 2009).

Antifungal assay using disc diffusion method

Testing of the plant extracts for antifungal activity was done by disc diffusion method described elsewhere (NCCLS, 2009). Briefly, the resulting inocula of $C$. albicans were swabbed in the amount of $1 \mathrm{~mL} / \mathrm{cm}^{2}$ over the surface of SDA plates. Then three filter discs uniformly loaded with given concentrations of the Av extract, corresponding solvents of Av extract as negative controls, and Ketoconazole (KTZ $20 \mathrm{mg} / \mathrm{mL}$ ) as positive controls were placed with sterile tweezers in three equidistances onto the prepared plates, respectively. All the testing was done in triplicate.

The zones of inhibition on the growth of test strains were defined by the area where visible growth had been inhibited completely. All the measurements of zone of inhibition were carried out by one single examiner (A. Mikaeili).

Antifungal assay with determination of the minimum inhibitory concentration (MIC)

For quantitative assays five doses of each extract $(20,40,80,160,320 \mathrm{mg} / \mathrm{dL})$ were added to SDA $(100 \mathrm{~mL})$ at $45^{\circ} \mathrm{C}$, these being mixed rapidly and poured into four $9.5 \mathrm{~cm}^{2}$ Petri dishes. After the agar had cooled down to room temperature $1.0 \times 10^{7} \mathrm{CFU} / \mathrm{mL}$ in NS were inoculated per each $\mathrm{cm}^{2}$ of Petri dishes. The MIC was taken as the lowest concentration of plant extract to inhibit growth of the fungus after $24 \mathrm{~h}$ and $48 \mathrm{~h}$ (NCCLS, 2009). Each experiment was repeated two times. Then, each extract that showed the highest antifungal activity against $C$. albicans was used in guinea pig models of cutaneous and systemic candidiasis.

In vivo antifungal assay: preparation of inocula

In this study, $C$. albicans isolates were selected as the infecting agent. Candida was grown on SDA slants at $30{ }^{\circ} \mathrm{C}$ for one week. The conidia were scraped from the plates in NS, centrifuged and washed twice in NS. The suspension was adjusted spectrophotometrically to a concentration of $1.0 \times 10^{7}$ conidia per $\mathrm{mL}$ (NCCLS, 2009). The working solution (WS) was prepared fresh in NS and $0.1 \mathrm{~mL}$ of WS used to inoculate the guinea pigs.

\section{Cutaneous candidiasis}

Male albino guinea pigs (mean body weight, $350 \mathrm{~g}$ ) were used in the study of in vivo anti-candidal activity. Briefly, guinea pigs were acclimatized for seven days by feeding on a commercial solid diet (Dan-e-pars Co., Kermanshah, Iran). After acclimatization, guinea pigs were divided into five groups ( $n=5$ in each group) on the basis of body weight: vehicle (the negative control animals received a vehicle containing $0.1 \mathrm{~mL}$ of normal saline solution plus $0.1 \mathrm{~mL}$ of distilled water; $\mathrm{NC}$ ), the positive control animals received $0.1 \mathrm{~mL}$ of $\mathrm{KTZ} 2 \%$; PC) and three other Av-treated, AE10\%, AE20\% and AE40\%, which received $0.1 \mathrm{~mL}$ of $10 \%, 20 \%$ and $40 \%$ aqueous extract of Av, respectively. The procedures for induction of cutaneous candidiasis were according to the previously described methodology (Niwano et al., 1994; Maebashi et al., 1994). Briefly, guinea pigs were anesthetized by intramuscular administration of a combination anesthetic containing ketamine and xylazine and their dorsum were clipped and shaved in an area of $2.5 \mathrm{~cm} \times 2.5 \mathrm{~cm}(6.25$ $\mathrm{cm}^{2}$ ). The marked area was inoculated with a fungal suspension $\left(0.1 \mathrm{~mL}, 2.0 \times 10^{7}\right.$ cells $)$ of $C$. albicans using a sterile pipette-tip and rubbed thoroughly. Prednisolone (Mitaka Pharmaceutical Co., Ltd., Tokyo, Japan) was subcutaneously administered four times (two days and immediately before and two and four days after the inoculation) at a dose of $30 \mathrm{mg} / \mathrm{kg}$ of body weight each time. In this part, formulations were topically applied to the infected area once a day for three consecutive days, starting on the fifth day postinfection.

\section{Evaluation of cutaneous candidiasis}

On the ninth day postinfection, all of the animals were deeply anesthetized by intramuscular administration of a combination anesthetic containing ketamine and xylazine and killed and the skin of the infected area was excised, minced with scissors, and homogenized in sterile physiological saline. A portion of the homogenate was cultured on a peptone yeast extract glucose agar $(2 \%$ Bacto Peptone, 1\% yeast extract, 2\% glucose, 1.5\% agar) plate for two days at $37{ }^{\circ} \mathrm{C}$. Colonies grown on the agar plate were counted to calculate the number of $\mathrm{CFU} / \mathrm{g}$. An animal was considered fungus positive when more than one fungal colony was counted (assay limit, less than 20 CFU/g infected site) (Niwano et al., 1994; Maebashi et al., 1994). 


\section{Systemic candidiasis}

To evaluate prophylactic effects of Av against systemic candidiasis, systemic candidiasis in guinea pigs was induced by a slight modification of the procedure of Van Cutsem et al. (1992). Briefly, guinea pigs were acclimatized for seven days by feeding on a commercial solid diet (Dan-e-pars Co., Kermanshah, Iran). After acclimatization, guinea pigs were divided into five groups ( $\mathrm{n}=5$ in each group) on the basis of body weight: vehicle (distilled water here; NC), KTZ 2\% (PC) and three other Av-treated, AE10\%, AE20\% and AE40\%, which received 10, 20 and $40 \%$ aqueous extract of $\mathrm{Av}$, respectively, in their drinking water ad libitum for ten days before induction of infection. Systemic candidiasis was obtained by intraperitoneal (i.p.) inoculation of $C$. albicans, $4000 \mathrm{CFU} / \mathrm{g}$ body weight. On the second day postinfection (day 12), after a 14- to 16-h fast, anesthesia was administered by an i.p. ketamine/xylazine injection and a blood sample was collected into a collection tube containing heparin via cardiac puncture and stored at -20 ${ }^{\circ} \mathrm{C}$ until analysis. After blood collection, the guinea pigs were decapitated and tissue specimens from the brain, lungs, heart, liver, spleen, eyes, stomach, intestines, kidneys, skeletal muscles, gonads (testes), lymph nodes, pancreas, thymus and adrenal glands of each animal were taken for qualitative and quantitative cultures. All the experiments were performed based on veterinary research ethics and this study was approved by the Iranian Society for the Prevention of Cruelty to Animals (ISPCA).

\section{Evaluation of systemic candidiasis}

The visceral organs of the infected animals were removed, placed in glass vials containing $10 \mathrm{~mL}$ of sterile saline and subsequently homogenized. One gram of the homogenates was made in sterile normal saline and cultured on Sabouraud glucose agar containing antibacterial antibiotics (20 IU penicillin and $40 \mu \mathrm{g} / \mathrm{mL}$ streptomycin). The plates were incubated at $37{ }^{\circ} \mathrm{C}$ for fourteen days, and the number of CFU per gram of tissue was determined (Khosravi et al., 2009).

\section{Statistical analyses}

The results are expressed as the mean \pm SEM. All statistical analyses were performed using SPSS 16.0 statistical software. Student's t-test was performed to determine any significant difference between different extracts for in vitro antifungal assays. Comparison of means for in vivo antifungal assessment was carried out using one-way analysis of variance (ANOVA) and Tukey HSD test. $p$-value $<0.05$ was considered statistically significant.

\section{Results}

\section{Essential oil chemical analysis}

Comprehensive GC/MS and GC/FID was used to analyze volatile components of Av top flowers in this study. The chemical constituents of EO are displayed in Table 1. The main components that isolated from EO of AV in the presence of different solvents that employed in this study were thymol in aqueous extract and hexadecanoic acid, 1,2-Benzenedicarboxylic acid, diisooctyl ester and phytol in both methanol and acetone extracts (Table 1).

In vitro antifungal assay

Antifungal assay using disc diffusion method

In the concentration 160 and $320 \mathrm{mg} / \mathrm{mL}$, aqueous extract of Av has significant higher antifungal activity in

Table 1. Comparative chemical composition (\%) of the essential oil of Astragalus verus (Black milkvetch) in the presence of different solvents.

\begin{tabular}{|c|c|c|c|c|}
\hline Extract & Compound & $t_{R}^{*}$ & Percent & $\mathrm{RI}^{* *}$ \\
\hline \multirow[t]{2}{*}{ aqueous $\dagger$} & methanol & 1.40 & - & - \\
\hline & thymol & 25.47 & 98 & 1181 \\
\hline \multirow[t]{4}{*}{ methanol $\uparrow$} & methanol & 1.39 & _ & _ \\
\hline & $n$-hexadecanoic acid & 51.26 & 56 & 1799 \\
\hline & phytol & 55.59 & 20 & 1899 \\
\hline & 1,2-benzenedicarboxylic acid, diisooctyl ester & 66.65 & 22 & 2157 \\
\hline \multirow[t]{4}{*}{ acetone } & acetone & 1.58 & _ & _ \\
\hline & $n$-hexadecanoic acid & 51.32 & 58 & 1800 \\
\hline & phytol & 55.61 & 10 & 1900 \\
\hline & 1,2-benzenedicarboxylic acid, diisooctyl ester & 66.69 & 22 & 2157 \\
\hline
\end{tabular}

Note: $\mathrm{t}_{\mathrm{R}}$ : retention time $(\mathrm{min}) ; * \mathrm{RI}$ : retention indices in elution from HP-1 column. $\dagger$ the essential oils of aqueous and methanol extracts were prepared in the presence of methanol as solvent. 
Table 2. In vitro antifungal activity of Astragalus verus extract on Candida albicans (determined by diameter of inhibition zones).

\begin{tabular}{lcccccc}
\hline & Extract & \multicolumn{4}{c}{ Dose $(\mathrm{mg} / \mathrm{mL})$} \\
\cline { 2 - 7 } & 20 & 40 & 80 & 160 & 320 \\
\hline methanol & NI & NI & NI & NI & NI \\
acetone & NI & NI & NI & NI & $20.6 \pm 0.333^{*}$ \\
aqueous & NI & NI & NI & $21.0 \pm 0.577 *$ & $25.0 \pm 0.577 *$ \\
ketoconazole & $29.4 \pm 0.444$ & $30.0 \pm 0.235$ & $29.4 \pm 0.293$ & $30.3 \pm 0.440$ & $30.1 \pm 0.309$ \\
\hline
\end{tabular}

Note: Values are mean \pm SEM (mm) of tri-plate test of the experiment; NI: no inhibition zone. *Shows significant difference compared with KTZ.

comparison to acetone extract $(p=0.000)$. Both aqueous and acetone extracts have significant lesser antifungal activity in comparison to KTZ at the concentration 320 $\mathrm{mg} / \mathrm{mL}$ ( $p=0.000$; Table 2$)$. The methanol extract showed no antifungal activity at the maximum dose $320 \mathrm{mg} / \mathrm{mL}$ that studied in the present investigation (Table 2).

\section{Antifungal assay with determination of MIC}

The aqueous extract showed MIC as $160 \mathrm{mg} / \mathrm{mL}$ while acetone extract showed MIC as $320 \mathrm{mg} / \mathrm{mL}$ for $C$. albicans.

\section{Cutaneous candidiasis}

The mean infection rate was higher in the skin of AE40\% group $\left(5.4 \pm 0.509 \times 10^{4} \mathrm{CFU} / \mathrm{g}\right)$ compared to KTZ-treated group $\left(2.2 \pm 0.374 \times 10^{4} \mathrm{CFU} / \mathrm{g} ; p=0.002\right.$; see Figure 1). However, AE10\% $\left(12.4 \pm 0.509 \times 10^{4} \mathrm{CFU} / \mathrm{g}\right)$ and AE20\% $\left(12.2 \pm 0.663 \times 10^{4} \mathrm{CFU} / \mathrm{g}\right)$ showed similar results compared to NC group $\left(12.8 \pm 0.374 \times 10^{4} \mathrm{CFU} / \mathrm{g} ; p=.978\right.$ and $p=0.911$, respectively; see Figure 1$)$. The CFU/g in AE $10 \%$ and AE $20 \%$ groups was the same $(p=0.998$; see Figure 1). The mean infection rate was lower in the skin of AE $40 \%$ group compared to NC group ( $p=0.000$; see Figure 1).

\section{Systemic candidiasis}

The mean infection rate was higher in the kidneys, lungs, heart, liver and spleen than those of the other organs as shown in NC group (Table 3). The mean infection rates of different organs decreased in the presence of KTZ and different concentrations of aqueous extracts of Av. The KTZ-treated group (PC) showed lower mean infection rate in all studied organs compared with NC group (Table 3). However, the mean infection rates in all organs except thymus and eyes of AE40\% group decreased significantly compared with NC group (Table 3). The AE $10 \%$ and AE20\% groups did not show significant difference in the mean infection rate of all organs in comparison to NC group (Table 3 ).

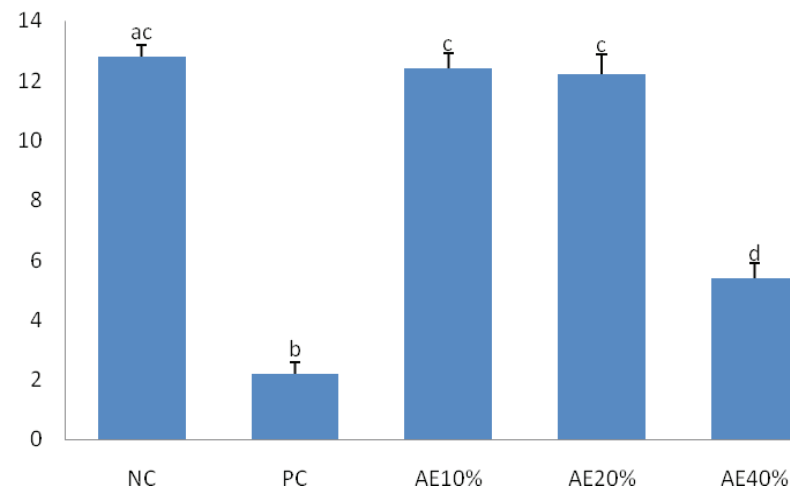

Figure 1. Contribution of aqueous extract of Astragalus verus to inhibition of Candida albicans in skin of guinea pigs. Note: NC: the negative control animals received a vehicle containing $0.1 \mathrm{~mL}$ of normal saline solution plus $0.1 \mathrm{~mL}$ of distilled water; PC: the positive control animals received $0.1 \mathrm{~mL}$ of ketoconazole 2\%; and three other AE10\%, AE20\% and AE40\% groups, which received $0.1 \mathrm{~mL}$ of 10,20 and $40 \%$ aqueous extract of Astragalus verus, respectively. *Values with various superscripts are significantly $(p<0.05)$ different in the Figure.

\section{Discussion}

This study shows that Astragalus verus Olivier, Fabaceae, can display anti-candidal activities both in the in vitro and in guinea pig models of cutaneous and systemic candidiases. In this sense, the aqueous extract of Av showed more anti-candidal activity than acetone extract, however methanol extract did not show any anticandidal activity in vitro as evaluated by disc diffusion method and determination of MIC.

As shown in Table 1, the chemical compositions of essential oils derived from both methanol and acetone extracts are approximately similar in both quality and quantity, however its direct in vitro anti-candidal activity of acetone extract must be related to other compounds that found in the whole acetone extract not in its essential oil. Three major compounds, hexadecanoic acid, phytol and 1,2-benzene dicarboxylic acid, diisooctyl ester, were identified by means of GC-MS analysis of the essential oils derived from acetone and methanol extracts of Av because the compounds participating in the mixtures in 
Table 3. Comparison of mean infection rates of various tissues according to colony forming unit (CFU) of Candida albicans in fungal culture.

\begin{tabular}{|c|c|c|c|c|c|}
\hline \multirow{2}{*}{ Tissue $\times 10^{4}$} & \multicolumn{5}{|c|}{ Group } \\
\hline & $\mathrm{NC}$ & $\mathrm{PC}$ & AE $10 \%$ & AE $20 \%$ & $\mathrm{AE} 40 \%$ \\
\hline Blood & $1.22 \pm 0.06$ & $0.21 \pm 0.09 *$ & $1.19 \pm 0.05$ & $1.27 \pm 0.02$ & $0.74 \pm 0.04^{*} \dagger$ \\
\hline Urine & $1.49 \pm 0.03$ & $0.51 \pm 0.05^{*}$ & $1.48 \pm 0.01 \dagger$ & $1.54 \pm 0.03 \dagger$ & $0.94 \pm 0.03 * \dagger$ \\
\hline Adrenal gds & $1.40 \pm 0.04$ & $0.21 \pm 0.09^{*}$ & $1.43 \pm 0.04 \dagger$ & $1.42 \pm 0.03 \dagger$ & $0.72 \pm 0.04^{*} \dagger$ \\
\hline Thymus & $0.21 \pm 0.09$ & $0.00 \pm 0.00^{*}$ & $0.27 \pm 0.12$ & $0.31 \pm 0.08$ & $0.06 \pm 0.06$ \\
\hline Pancreas & $1.96 \pm 0.02$ & $0.61 \pm 0.04 *$ & $1.93 \pm 0.02 \dagger$ & $1.95 \pm 0.02 \dagger$ & $0.99 \pm 0.90 * \dagger$ \\
\hline Lymph nds & $0.81 \pm 0.03$ & $0.12 \pm 0.07 *$ & $0.72 \pm 0.04 \dagger$ & $0.78 \pm 0.06 \dagger$ & $0.63 \pm 0.05^{* \dagger}$ \\
\hline Gonads & $1.69 \pm 0.03$ & $0.49 \pm 0.05^{*}$ & $1.72 \pm 0.04 \dagger$ & $1.74 \pm 0.03 \dagger$ & $0.78 \pm 0.04^{*} \dagger$ \\
\hline Muscles & $0.91 \pm 0.02$ & $0.00 \pm 0.00^{*}$ & $0.85 \pm 0.03 \dagger$ & $0.82 \pm 0.04 \dagger$ & $0.12 \pm 0.07^{*}$ \\
\hline Kidneys & $2.97 \pm 0.02$ & $1.28 \pm 0.03^{*}$ & $2.96 \pm 0.00 \dagger$ & $2.95 \pm 0.00 \dagger$ & $1.68 \pm 0.01^{* \dagger}$ \\
\hline Gut & $2.32 \pm 0.00$ & $0.71 \pm 0.03 *$ & $2.30 \pm 0.00 \dagger$ & $2.30 \pm 0.00 \dagger$ & $1.13 \pm 0.04 * \dagger$ \\
\hline Stomach & $2.05 \pm 0.01$ & $0.43 \pm 0.05^{*}$ & $2.05 \pm 0.01 \dagger$ & $2.04 \pm 0.01 \dagger$ & $0.94 \pm 0.03^{*} \dagger$ \\
\hline Eyes & $0.21 \pm 0.09$ & $0.00 \pm 0.00^{*}$ & $0.21 \pm 0.09$ & $0.15 \pm 0.09$ & $0.12 \pm 0.07$ \\
\hline Spleen & $2.33 \pm 0.01$ & $0.61 \pm 0.04 *$ & $2.32 \pm 0.00 \dagger$ & $2.32 \pm 0.01 \dagger$ & $1.01 \pm 0.03 * \dagger$ \\
\hline Liver & $2.43 \pm 0.00$ & $0.81 \pm 0.03^{*}$ & $2.41 \pm 0.00 \dagger$ & $2.41 \pm 0.01 \dagger$ & $1.06 \pm 0.03^{*} \dagger$ \\
\hline Heart & $2.54 \pm 0.00$ & $0.92 \pm 0.02 *$ & $2.57 \pm 0.05 \dagger$ & $2.52 \pm 0.00 \dagger$ & $1.21 \pm 0.02 * \dagger$ \\
\hline Lung & $2.69 \pm 0.00$ & $1.12 \pm 0.03^{*}$ & $2.67 \pm 0.00 \dagger$ & $2.67 \pm 0.00 \dagger$ & $1.42 \pm 0.03 * \dagger$ \\
\hline Brain & $0.69 \pm 0.02$ & $0.00 \pm 0.00^{*}$ & $0.68 \pm 0.06 \dagger$ & $0.63 \pm 0.05 \dagger$ & $0.12 \pm 0.07 *$ \\
\hline
\end{tabular}

Note: *Shows significant difference compared to NC group while $\dagger$ shows significant difference compared to PC or ketoconazole-treated group. Data were expressed as mean \pm SEM and $p$-value $<0.05$ was considered statistically significant.

percentages lower than $10 \%$ were not presented in Table I. The phytol content of methanol extract was twice the amount of acetone extract. Thymol was the major compound that found in the essential oil derived from aqueous extract of $\mathrm{Av}$ and consisted $98.0 \%$ of essential oil. Many fatty acids are known to have antibacterial and antifungal properties. For example, hexadecanoic acid and oleic acids are known to have potential antibacterial and antifungal activity (Dilika et al., 2000; McGraw et al., 2002; Seidel \& Taylor, 2004; Bodoprost \& Rosemeyer, 2007). The direct anti-candidal activity of acetone extract of Av might be the result of hexadecanoic acid and/or phytol action. It seems this antifungal activity is a dose dependent because at dose $1.0 \mathrm{mg} / \mathrm{mL}, \mathrm{n}$-hexadecanoic acid did not show any inhibitory action against $C$. albicans (Kabara et al., 1972). Phytol is a diterpene which is present in higher concentration in the methanol extract of Av. The phytol was observed to have dosedependent antibacterial activities against Staphylococcus aureus (Inoue et al., 2005). 1,2-benzene dicarboxylic acid, diisooctyl ester also known as diisooctyl phthalate (DIOP) constitutes $22 \%$ of the essential oils derived from acetone and methanol extracts of Av. This constituent may therefore not be injurious to health and its antimicrobial activity has not reported yet. However its insecticidal, larvicidal and pesticidal activities have been reported previously (Hema et al., 2011).
To our knowledge, there is no similar study that investigated the tissue distribution of C. albicans following inducing an experimental systemic candidiasis in guinea pigs. In this study, the highest counts of $C$. albicans were recovered from the kidneys, followed by the lungs, heart, liver and spleen in NC group. These results are consistent with the distribution of C. albicans in the tissues of immunocompromised dogs on day 2 after challenge (Khosravi et al., 2009). However, the highest mean infection rate was reported in the lungs in immunocompromised dogs (Khosravi et al., 2009). The highest counts of $C$. albicans were recovered from the kidneys in the present investigation, probably are related to the prominent role of kidneys to excrete $C$. albicans throughout two days postinfection. As previously reported, the lowest counts of C. albicans were recovered from thymus and eyes (Khosravi et al., 2009). The PC group showed overt anti-candidal activity compared to the all groups that received aqueous extract. Ketoconazole $2 \%$ (PC) completely inhibited the growth of C. albicans in thymus, muscles, eyes and brain. Also, the minimum $\mathrm{CFU} / \mathrm{g}$ skin was recorded in KTZ-treated group in the cutaneous candidiasis in the current investigation. In this form of candidiasis only the highest amount of aqueous extract of Av in AE $40 \%$ group showed considerable anticandidal effects when compared to $\mathrm{NC}$ group.

In this study, supplementation of aqueous extracts 
of Av in drinking water prevented the heavy burden of $C$. albicans in different tissues of guinea pig. In this regard, the mean infection rates of all studied tissues except thymus and eyes $(p>0.05)$ were considerably decreased for the AE40\% group $(p<0.05)$, while the AE $10 \%$ and AE4\% groups showed a moderate decrease when compared to the NC group $(p>0.05)$. This means that the high amount of aqueous extract of Av in drinking water may exert an in situ anti-candidal activity or may prevent distribution or lodging of $C$. albicans in different tissues. Thymol was found as a main aromatic substance in an essential oil derived from aqueous extract of $\mathrm{Av}$ and the anti-candidal activity of aqueous extract of Av might be the result of thymol. Thymol is part of a naturally occurring class of compounds known as biocides, with strong antimicrobial attributes when used alone or with other biocides. The antibacterial, antioxidant and antifungal activities of thymol were the subject of many studies (Palaniappan \& Holley, 2010; Ündeğer et al., 2009; Ahmad et al., 2010). Particularly, thymol has been successfully used in vitro against pathogenic fungi, including Aspergillus, C. albicans and moulds (Giordani et al., 2004; Shin \& Kim, 2004). Thymol has been shown to be an effective fungicide, particularly against fluconazole clinical C. albicans isolates, including fluconazole-resistant and fluconazole-susceptible $C$. albicans strains, when combined with fluconazole or amphotericin B, although it shows weak antifungal activity when used alone (Guo et al., 2009; Ahmad et al., 2010).

The improvement of cutaneous candidiasis following topical application of aqueous extract of Av may be related to the boosting of immune systems. The immunostimulating activity of Astragalus species has been subject of several studies (Kong et al., 2004; Hu et al., 2006). Twenty-eight patients with systemic lupus erythematosus had significantly decreased natural killer cell activity when compared to normal controls. Preincubation of their peripheral blood mononuclear cells with Astragalus stimulated natural killer cell cytotoxicity in systemic lupus erythematosus patients and in healthy controls (Zhao, 1992). Beside its immunostimulating activity, other studies have shown the direct antimicrobial activity of different extracts and pure compounds that derived from Astragalus species. In mice infected with coxsackie B-3 virus, Astragalus inhibited viral replication in the myocardial tissue while improving abnormal myocardial electric activity (Lee et al., 2007). The antimicrobial and antifungal properties of several crude extracts from different parts of other Astragalus species have been reported (Bisignano et al., 1994; El Sebakhy et al., 1994; Pistelli et al., 2002). The aqueous extract of Av showed maximum antifungal activity in the present study. Antimycotic activity of aerial parts of Astragalus verrucosus was observed on more polar extracts as well (Pistelli et al., 2002). The aqueous extract of Av at dose
$40 \%$ showed an acceptable efficacy in comparison to licensed compound KTZ and CFUs of skin and internal organs were significantly reduced and continued to decline in contrast to the progressive infection observed in the untreated animals throughout the observation period. Further studies are required to find the active compound in the aqueous extract of Av that demonstrates antifungal or possibly immune-modulating activities. In this sense, the active compounds including of pure saponins and astraverrucins I-VI derived from Astragalus verrucosus, antimicrobial isoflavans, astragaluquinone, 8-methoxyvestitol and 7-hydroxy$2^{\prime}, 3^{\prime}, 4^{\prime}$-trimethoxyisoflavan were isolated from roots of Astragalus alexandrinus and A. trigonus showed an appreciable antimicrobial activity (El Sebakhy et al., 1994; Pistelli et al., 2002).

In conclusion, we found aqueous extract of Av has antifungal activity in vitro and it exerted a significant anti-candidal effect against cutaneous and systemic candidiasis in guinea pig model. The detection of antifungal activity of Av gives the claims by traditional healers a significantly high credibility. However, in order to develop an Astragalus-based formulation for the treatment or control of candidiasisrelated complications, more research will be needed to identify the whole active ingredients in Av and their mechanisms of action.

\section{Acknowledgements}

This project was financed by Department of Pharmacology, School of Pharmacy, Kermanshah University of Medical Sciences, Kermanshah, Iran.

\section{References}

Adams RP 1996. Identification of essential oil components by gas chromatography mass spectroscopy. Allured Publishing Corporation, Carol Stream, IL.

Ahmad A, Khan A, Yousuf S, Khan LA, Manzoor N 2010. Proton translocating ATPase mediated fungicidal activity of eugenol and thymol. Fitoterapia 81: 1157-1162.

Ali-Shtayeh MS, Yaghmour RMR, Faidi YR, Khalid S, AlNuri MA 1998. Antimicrobial activity of 20 plants used in folkloric medicine in the Palestinian area. $J$ Ethnopharmocol 60: 265-271.

Bisignano G, Iauk L, Kirjavainen S, Galati EM 1994. Antiinflammatory, analgesic, antipyretic and antibacterial activity of Astragalus siculus Biv. Pharm Biol 32: 400405 .

Bodoprost J, Rosemeyer H 2007. Analysis of phenacylester derivatives of fatty acids from human skin surface sebum by reversed-phase HPLC: chromatograpic mobility as a function of physico-chemical properties. Int J Mol Sci 8: 1111-1124. 
Chalechale A, Karimi I 2009. Antiparasitic remedies in Kurdish ethnopharmacology: a neglected treasure trove. Proceedings of the 5th International Joint Conference of Agricultural Sciences. Saint Petersburg, Russia.

Chaudhry NA, Tariq P 2008. In vitro antibacterial activities of Kalonji, Cumin and Poppy seeds. Pak J Bot 40: 461467.

Clemons KV, Stevens DA 2000. Treatment of orogastrointestinal candidosis in SCID mice with fluconazole alone or in combination with recombinant granulocyte colony stimulating factor or interferon- $\gamma$. Med Mycol 38: 213219.

Clemons KV, Stevens DA 2001. Efficacy of ravuconazole in treatment of mucosal candidosis in SCID mice. Antimicrob Agents Ch 45: 3433-3436.

Dilika F, Bremner PD, Meyer JJ 2000. Antibacterial activity of linoleic and oleic acids isolated from Helichrysum pedunculatum: a plant used during circumcision rites. Fitoterapia 71: 450-452.

El Sebakhy NA, Asaad AM, Abdallah RM, Toaima SM, AbdelKader MS, Stermitz FR 1994. Antimicrobial isoflavans from Astragalus species. Phytochemistry 36: 13871389.

Giordani R, Regli P, Kaloustian J, Mikaïl C, Abou L, Portugal H 2004. Antifungal effect of various essential oils against Candida albicans. Potentiation of antifungal action of amphotericin B by essential oil from Thymus vulgaris. Phytother Res 18: 990-995.

Guo N, Liu J, Wu X, Bi X, Meng R, Wang X, Xiang H, Deng X, Yu L 2009. Antifungal activity of thymol against clinical isolates of fluconazole-sensitive and -resistant Candida albicans. J Med Microbiol 58: 1074-1079.

Hema R, Kumaravel S, Alagusundarum K 2011. GC-MS study on the bioactive components and anti-cancer activities of Solanum surattense. Cancer Biol 1: 13-17.

Hu YL, Xu CL, Wang YZ, Li YJ, Liu JX, Feng J 2006. Effect of dried roots of Astragalus membranaceus in the diets of young growing pigs on growth performance and immune function. J Anim Feed Sci 15: 599-607.

Inoue Y, Hada T, Shiraishi A, Hirose K, Hamashima H, Kobayashi S 2005. Biphasic effects of geranylgeraniol, teprenone, and phytol on the growth of Staphylococcus aureus. Antimicrob Agents Ch 49: 1770-1774.

Kabara JJ, Swieczkowski DM, Conley AJ, Truant JP 1972. Fatty Acids and derivatives as antimicrobial agents. Antimicrob Agents Ch 2: 23-28.

Karaman I, Sahin F, Güllüce M, Öğütçü H, Sengül M, Adıgüzel A 2003. Antimicrobial activity of aqueous and methanol extracts of Juniperus oxycedrus L. J Ethnopharmacol 85: 231-235.

Khosravi AR, Mardjanmehr H, Shokri H, Naghshineh R, Rostamibashman M, Naseri A 2009. Mycological and histopathological findings of experimental disseminated candidiasis in dogs Iranian. Iran J Vet Res 10: 228-234.

Kong XF, Hu YL, Rong R, Wang DY, Li XR 2004. Effects of chinese herbal medicinal ingredients on peripheral lymphocyte proliferation and serum $\mathrm{Ab}$ titer after vaccination in chicken. Int Immunopharmacol 4: 975982.

Lee SJ, Oh SG, Seo SW, Ahn HJ, Geum D, Cho JJ, Park CS 2007. Oral administration of Astragalus membranaceus inhibits the development of DNFB-induced dermatitis in NC/Nga Mice. Biol Pharm Bull 30: 1468-1471.

Maebashi K, Itoyama T, Uchida K, Suegara N, Yamaguchi H 1994. A novel model of cutaneous candidiasis produced in predinsolone-treated guinea pigs. $J$ Med Mycol 32: 349-359.

McGraw LJ, Jager AK, Van Staden J 2002. Isolation of antibacterial fatty acids from Schotia brachypetala. Fitoterapia 73: 431-433.

Mikaeili A, Modaresi M, Karimi I, Ghavimi H, Modaresi M, Fathi M, Jalilian N 2011. Antifungal activities of Astragalus verus Olivier. against Trichophyton verrucosum on in vitro and in vivo guinea pig model of dermatophytosis. Mycoses doi: 10.1111/j.14390507.2011.02090. $\mathrm{x}$

National Committee for Clinical Laboratory Standards: NCCLS 2009. Reference method for broth dilution antifungal susceptibility testing of yeasts, approved standardsecond edition M27-A2. National Committee for Clinical Laboratory Standards, Wayne, PA, USA.

Niwano Y, Seo A, Kanai K, Hamaguchi H, Uchida K, Yamaguchi H 1994. Therapeutic efficacy of lanoconazole, a new imidazole antimycotic agent, for experimental cutaneous candidiasis in guinea pigs. Antimicrob Agents Ch 38 : 2204-2206.

Palaniappan K, Holley RA 2010. Use of natural antimicrobials to increase antibiotic susceptibility of drug resistant bacteria. Int J Food Microbiol 140: 164-168.

Pistelli L, Bertoli A, Lepori E, Morelli I, Panizzi L 2002. Antimicrobial and antifungal activity of crude extracts and isolated saponins from Astragalus verrucosus. Fitoterapia 73: 336-339.

Primo V, Rovera M, Zanon S, Oliva M, Demo V, Daghero J, Sabini L 2001. Determination of the antibacterial and antiviral activity of the essential oil from Minthostachys verticillata (Griseb.) Epling. Rev Argent Microbiol 33: 113-117.

Runyoro DK, Matee M, Ngassapa OD, Joseph CC, Mbwambo $\mathrm{CH}$ 2006. Screening of Tanzanian medicinal plants for anti-candida activity. BMC Complem Altern M 6: doi:10.1186/1472-6882-6-11.

Seidel V, Taylor PW 2004. In-vitro activity of extracts and constituents of Pelagonium against rapidly growing mycobacteria. Int J Antimicrob Ag 23: 613-619.

Shibamoto T 1987. Retention indices in essential oil analysis, capillary gas chromatography in essential oil analysis. Walter Huething Verlag, New York, NY.

Shin S, Kim JH 2004. Antifungal activities of essential oils from Thymus quinquecostatus and T. magnus. Planta 
Med 70: 1090-1092.

Ündeğer Ü, Basaran A, Degen GH, Basaran N 2009. Antioxidant activities of major thyme ingredients and lack of (oxidative) DNA damage in V79 Chinese hamster lung fibroblast cells at low levels of carvacrol and thymol. Food Chem Toxicol 47: 2037-43.

Van Cutsem J, Van Gerven F, Oris M, Van der Flaes M 1992. Oral prophylaxis with Itraconazole of experimental aspergillus and Candida infections. Int Meeting on Systemic Fungal Infections, Nijmegen 1991. Chemotherapy 38 (suppl 1): 55-55.

Waring EJ 2009. Pharmacopoeia of India. Charleston: BiblioBazaar LLC.

Zhao XZ 1992. Effects of Astragalus membranaceus and
Tripterygium hypoglancum on natural killer cell activity of peripheral blood mononuclear cells in systemic lupus erythematous. Chung Kuo Chung Hsi I Chieh Ho Tsa Chih 12: 679-671.

\section{*Correspondence}

Isaac Karimi

Department of Biochemistry, Physiology and Pharmacology, College of Veterinary Medicine, Razi University

Kermanshah, Iran

karimiisaac@razi.ac.ir

Tel.: +9883183225998329540

Fax.: +98 8318320041 